1 Population Health Sciences Institute, Newcastle University, Newcastle upon Tyne, UK

2 Institute of Cardiovascular and Medical Sciences. University of Glasgow, Glasgow, UK

3 University of Hertfordshire, Hatfield, UK

4 University of Nottingham Royal Derby Hospital, Derby, UK

5 School of Health Care, University of Leeds, Leeds, UK

Correspondence to: Barbara Hanratty Barbara.hanratty@newcastle.ac.uk Cite this as: BMJ 2020;369:m2463 http://dx.doi.org/10.1136/bmj.m2463 Published: 24 June 2020

\title{
Covid-19 and lack of linked datasets for care homes
}

\author{
The pandemic has shed harsh light on the need for a live minimum dataset
}

Barbara Hanratty, ${ }^{1}$ Jennifer Kirsty Burton, ${ }^{2}$ Claire Goodman, ${ }^{3}$ Adam L Gordon, ${ }^{4}$ Karen Spilsbury ${ }^{5}$

Residents of care homes are centre stage in the covid-19 pandemic for all the wrong reasons. Home to vulnerable people with complex needs, these settings should have been an obvious focus and priority in pandemic planning. ${ }^{1}$ Almost half of newly admitted residents in the UK are transferred from hospitals, creating a resident population with wide ranging needs spread across 450 ooo beds in almost 11 ooo homes. ${ }^{23}$ This is more than double the number of beds in NHS hospitals, ${ }^{3}$ but unlike NHS facilities most homes are privately owned, with residents responsible for some or all of the costs of their care. Yet as covid-19 spread across the UK, minutes suggest that the government's Scientific Advisory Group for Emergencies (SAGE) discussed care homes only twice in the first five months of 2020.4

The covid-19 pandemic has placed a spotlight on how little is known about this sector, and the lack of easily accessible, aggregated data on the UK care home population. Basic information that could be used to inform service responses, such as the number of residents in homes with and without nursing care, and hospital admissions and deaths among them, is difficult to locate. ${ }^{5}$ It is not simply lack of data that is the problem, it is the number of different bodies that are collecting information, and the absence of standardisation and cross sector cooperation in how data are collated, shared, and used.

Care homes collect and use data every day on the needs, health, and wellbeing of their residents, and a growing number of homes have sophisticated information systems to monitor medications, support care planning, and much more. Health services also keep routine records about homes' residents, but these data are, rightly, difficult to access. External bodies such as the Care Quality Commission in England and the Care Inspectorate in Scotland collect information for regulation and quality assurance, including data on deaths and disease outbreaks. ${ }^{67}$ Figures on staffing are collated by managers' organisation Skills for Care and the Scottish Social Services Council. ${ }^{8}$ None of these sources, however, provide timely information in a usable format that could inform urgent responses to the covid-19 pandemic.

\section{Real time data}

Some of the most innovative responses to the pandemic have emerged at regional level. For example, Health Innovation Manchester has a care data tracker that allows homes to provide real time information about residents to general practices and hospitals. ${ }^{9}$ In north east England digital collection of national early warning scores and linking of routine health and social care data has accelerated during the pandemic. ${ }^{10}$ And a capacity tracking app was introduced in England to generate data on care home bed occupancy and staffing. ${ }^{11}$

To date there has been no national, systematic approach in the UK to develop care home datasets or to exploit their full potential to enhance residents' care. We are collaborating on a study to design, develop, and implement a minimum dataset for UK care homes such as that developed in the US for the Centers for Medicare and Medicaid Services. ${ }^{12}$ The learning from covid-19 will directly inform this work, and we intend that any minimum dataset built for UK care homes should be a resource to support residents' care and not just a tool for regulation or cost containment.

Longitudinal data on infections and deaths in care homes would have allowed real time monitoring from the start of the pandemic, early detection of problems, and targeted appropriate interventions. This could have yielded insights into the natural course of covid-19 in care homes, underpinned evidence based guidance, and identified triggers for service responses. As patients were discharged from hospitals to care homes after treatment, data on the health of residents would have been invaluable to develop strategies to protect people at greatest risk and minimise further spread within homes. Such data could also inform the need for bespoke surveillance systems for future pandemic waves.

Other countries have introduced care home minimum datasets, but none have been adapted for, or adopted into, routine UK care. In the US nursing homes are federally mandated to contribute to a minimum dataset, and payments are contingent on participation. ${ }^{13}$ Related measures, such as the Resident Assessment Instrument and Dutch National Measurement of Care Problems, are in use in Europe. ${ }^{1415}$ None, however, provide the comprehensive information at the individual resident, care home, or organisational levels needed for health monitoring, and all have faced challenges in implementation.

Timely and accessible data on residents' health, wellbeing, and service use could support rational planning and delivery of care tailored to residents' needs, something that UK health and social care sectors have often struggled to do. Data are also vital for research, and for monitoring equity in outcomes and access to care. Workloads are already high in care homes, though, and it is crucial that data collection is not a burden on staff.

This pandemic has focused public and political attention on the needs of people in care homes, exposing a long established gap in data intelligence and prioritisation of needs. Such information could 
have made the difference between rapid, effective responses and the high rates of infection and mortality that have been the hallmark of covid-19. Political decisions on the funding and organisation of social care over decades have led us to this point. ${ }^{16}$ As societies question these choices and seek better ways of looking after our older citizens, ensuring that care homes are part of a data system that works to support and protect residents must be a priority.

Competing interests: The BMJ has judged that there are no disqualifying financial ties to commercial companies. The authors have no other interests to declare.

Provenance and peer review: Not commissioned; externally peer reviewed.

We thank the other members of the DACHA (Developing research resources and minimum data set for care homes' adoption and use) study team: Gizdem Akdur, Lisa Irvine, Massirfufulay Musa, Sarah Kelly, Andy Cowan, Guy Peryer, Anne Killett, Priti Biswas, Jessica Blake, lan Lang, Anne-Marie Towers, Susan Fortescue, Julienne Meyer, Adam Steventon, and Arne Walters. The DACHA study is funded by the National Institute for Health Research (NIHR) Health Service Research and Delivery programme (HS\&DR NIHR127234) and supported by the NIHR ARC East of England. BH, ALG, and KS are supported by NIHR ARCs North East and North Cumbria, East Midlands, Yorkshire and Humber. The views expressed are those of the authors, and not necessarily those of the NIHR, NHS, or Department of Health and Social Care.

1 British Geriatrics Society. Quest for quality: British Geratrics Society joint working party inquiry into the quality of healthcare support for older people in care homes. A call for leadership, partnership and quality improvement. London, 2011.

2 Burton JK, Lynch E, Love S, Rintoul J, Starr JM, Shenkin SD. Who lives in Scotland's care homes? Descriptive analysis using routinely collected social care data 2012-16. J R Coll Physicians Edinb 2019:49:12-22. doi: 10.4997/JRCPE.2019.103 pmid: 30838985

3 Laing W. Care homes for older people UK market report. 30th ed. LaingBuisson, 2019.

$4 \quad$ Lintern S. Coronavirus: care homes mentioned only twice in five months of Sage minutes. Independent 2020 May 31. https://www.independent.co.uk/news/health/coronavirus-sagemeetings-care-homes-a9541321.html

5 Naylor A. Unforgotten: the people, lost and found, in receipt of social care. Future Care Capital Social Care Data Finder, May 2020. https://futurecarecapital.org.uk/latest/social-care-data-finder/

6 Care Quality Commission. The state of health care and adult social care in England: 2018-19. https://www.cqc.org.uk/sites/default/files/20191015_stateofcare1819_summary.pdf

7 Care Inspectorate. Notifications. https://www.careinspectorate.com/index.php/notifications.

8 Skills for Care. Adult social care workforce data. https://www.skillsforcare.org.uk/adult-socialcare-workforce-data/adult-social-care-workforce-data.aspx

9 NHS England/ North East Commissioning Support Unit. Capacity tracker. https://www.necsu.nhs.uk/wp-content/uploads/2018/07/Capacity-tracker-DL-leaflet-final-28.01.20.pdf app

10 Health Innovation Manchester. Covid-19 digital care homes. https://healthinnovationmanchester.com/our-work/covid-19-digital-care-homes/

11 Barker RO, Stocker R, Russell S, etal. Distribution of the National Early Warning Score (NEWS) in care home residents. Age Ageing 2019;49:141-5. doi: 10.1093/ageing/afz130 pmid: 31813952

12 Medicare. Long term care facility resident assessment instrument 3.0 user's manual. 2015. https://www.cms.gov/Medicare/Quality-Initiatives-Patient-Assessment-Instruments/NursingHomeQualitylnits/Downloads/MDS-30-RAl-Manual-V113.pdf.

13 Stosz L, Carpenter I. Developing the use of MDS/RAI reports for UK care homes. Joseph Rowntree Foundation, 2008. https://www.jif.org.uk/report/developing-use-mds-rai-reports-uk-care-homes

14 van Nie-Visser NC, Schols JMGA, Meesterberends E, Lohrmann C, Meijers JMM, Halfens RJG. An international prevalence measurement of care problems: study protocol. J Adv Nurs 2013;69:e18-29. doi: 10.1111/jan.12190 pmid: 23941057

15 Goodman C, et al. Developing research resources and a minimum dataset for care homes' adoption and use (the DACHA study). https://fundingawards.nihr.ac.uk/award/NIHR127234

16 Pollock AM, Clements L, Harding-Edgar L. Covid-19: why we need a national health and social care service. BM/2020;369:m1465. doi: 10.1136/bmj.m1465 pmid: 32291259

This article is made freely available for use in accordance with BMJ's website terms and conditions for the duration of the covid-19 pandemic or until otherwise determined by BMJ. You may use, download and print the article for any lawful, non-commercial purpose (including text and data mining) provided that all copyright notices and trade marks are retained. 